\title{
Adaptive Behavior Assessment System, Parent Rating Form
}

National Cancer Institute

\section{Source}

National Cancer Institute. Adaptive Behavior Assessment System, Parent Rating Form.

NCI Thesaurus. Code C121188.

A comprehensive norm-referenced assessment of the adaptive skills of individuals ages 5

to 21 years that is used to evaluate children with intellectual and developmental

disabilities. This form is completed by parents or others responsible for the child's

primary care. 